On course
International fusion
reactor moves a
step closer
p392

\title{
Anthropologists in turmoil over allegations of misconduct
}

Rex Dalton, San Francisco

Researchers clashed at the annual meeting of the American Anthropological Association (AAA) over a book that has generated a storm of criticism for anthropologists since it was published earlier this year.

Written by journalist Patrick Tierney, Darkness in El Dorado: How Scientists and Journalists Devastated the Amazon describes a study of the Venezuelan Yanomami people. In the book, Tierney claims that data were manipulated, the Yanomami tribe abused, and that research techniques contributed to the deaths of natives through illness or warfare. The AAA has now set up an ethics inquiry to investigate these allegations.

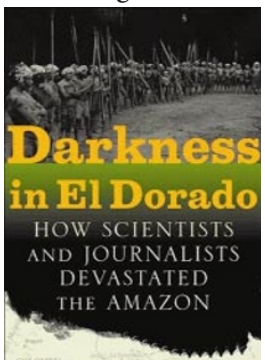

Tierney's book alleges that anthropologist Napoleon Chagnon, from the University of California at Santa Barbara, deceased geneticist James Neel of the University of Michigan and their colleagues PATRICK TIERNEY may have contributed to a measles or fever epidemic by inoculating Yanomami with a suspect vaccine. The book also alleges that they promoted warfare and violated the culture of the primitive peoples.

Chagnon, who declined an invitation to take part in last week's meeting, has denied the allegations, speaking through supporters and in public statements. Chagnon's own 1968 book, Yanomamo: The Fierce People, which describes his studies of the tribe, has since become a major anthropology text.

Tierney's allegations were discussed at two extraordinary sessions of the AAA meeting. The first three-hour session included contributions by a physician who is an authority on measles vaccines, a medical historian, an expert on informed consent, a physician, an anthropologist and tribe member from Venezuela, and William Irons, a Northwestern University anthropologist, who spoke on Chagnon's behalf.

With Tierney sitting at the other end of the table, Irons lambasted the book as rife with falsehoods, accused the author

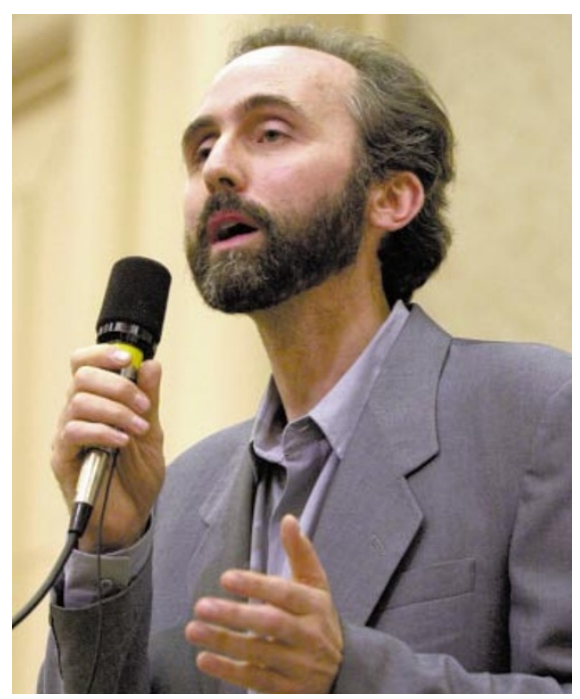

No apologies: Patrick Tierney defends his book from criticism at the anthropology meeting.

of being duped by Chagnon's enemies and urged AAA members to boycott the book. Tierney's critics also pointed to statements released by researchers at the University of California at Santa Barbara, the University of Michigan and the National Academy of Sciences that have harshly criticized the book (see Nature 408, 283;2000).

After all the panel members had spoken, a visibly shaken Tierney defended his book, asking "everyone to work together" to address the issues raised in it. "Hopefully, we can find some light from this darkness," he concluded. Tierney's talk was greeted with a round of applause that was only exceeded by that given to the Venezuelan tribal member's plea for native peoples.

During the second session the next evening, dozens of anthropologists gave emotional three-minute statements. Several speakers denounced the previous session, saying panellists had shown detestable, colonial "arrogance" as they sought to undermine Tierney's book. Other speakers launched new verbal assaults on Tierney, calling for investigations and censure of some of the anthropologists who had assisted him.

And several speakers lamented that the debate focused too much on the accused researchers, and not enough on the vulnerable Yanomami. One anthropologist said: "The Yanomami have been used and abused by outsiders for years. What have the Yanomami gotten for 30 years of research?"

Louise Lamphere, an anthropologist at the University of New Mexico and current president of the association, announced that a special panel-drawn from its committees on ethics and human rights - would conduct an inquiry into the allegations. Early next year, the AAA's executive board will consider the panel's recommendations and decide whether to launch a formal ethics investigation.

But the public row over Tierney's book is already prompting consideration of modifications to some of the techniques of anthropology. The AAA's Ethics Committee has begun developing new proposed guidelines for anthropologists conducting field research.

The guidelines will deal directly with many of the issues raised in the book. For example, Tierney alleges that scientists and journalists failed to aid dying Yanomami, and the guidelines will advise researchers on the provision of emergency medical care for study subjects. They will discuss what remuneration subjects should receive (Tierney charges that machete distributionled to more deaths from inter-village warfare), and what constitutes appropriate informed consent, particularly for remote peoples who face language barriers (Tierney alleges that experiments were conducted on Yanomami without their consent).

Scientific leaders in Venezuela and Brazil also announced inquiries. Venezuela placed a moratorium on permits allowing research on indigenous people such as the Yanomami. And the Brazilian anthropological association issued a statement saying it will work with the AAA to strengthen guidelines for studying native populations there.

Anthropologist Jesus Cardozo, who represented Venezuela's office of indigenous affairs at the meeting, says his country is "committed to a fair and impartial analysis" of the allegations of "the most serious violations of human rights". Tierney's book, Cardozo says, "moves us to reflect: were human subjects reduced to human objects?". 